\title{
Planos de amostragem no desenvolvimento inicial do cafeeiro sob irrigação ${ }^{1}$
}

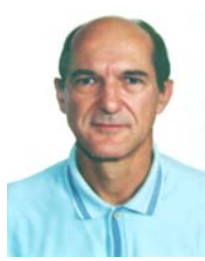

Augusto R. de Morais ${ }^{2}$, Myriane S. Scalco ${ }^{3}$, Alberto Colombo ${ }^{4}$, Manoel A. de Faria ${ }^{4}$, Carlos H. M. de Carvalho ${ }^{5}$ \& Leandro C. Paiva ${ }^{5}$

1 Parte do subprojeto financiado pelo PNP\&D EMBRAPA/Café

2 Departamento de Ciências Exatas/UFLA, C.P. 3037, CEP 37200-000, Lavras, MG. Fone: (35)3829.1371, E-mail: armorais@ufla.br (Foto)

3 Departamento de Agricultura/UFLA. Fone: (35) 3829.1776, Fax: (35) 3829.1301, E-mail: msscalco@ufla.br

${ }^{4}$ Departamento de Engenharia/UFLA. Fone: (35) 3829-1388, E-mail: acolombo@ufla.br e E-mail: mafaria@ufla.br

${ }^{5}$ UFLA/DAG. Fone: (35)38212767,E-mail: carvalho.ch@uol.com.br; E-mail: Icpaivas@uol.com.br

Protocolo 119 - 23/8/2002 - Aprovado em 14/6/2005

\begin{abstract}
Resumo: Este trabalho teve por objetivo avaliar características de plantas de café cultivar RubiMG1192 e, através da variabilidade dessas características, estabelecer planos de amostragem para orientar projetos na cultura do café, em desenvolvimento inicial. O experimento está instalado na área experimental do Departamento de Agricultura da Universidade Federal de Lavras, em Lavras, MG. O delineamento experimental foi em blocos casualizados, com quatro repetições, e os tratamentos constam das combinações de densidades de plantio definidas pelos espaçamentos $2500(4,0 \times 1,0 \mathrm{~m}), 3000(3,0 \times 1,0 \mathrm{~m}), 5000(2,0 \times 1,0 \mathrm{~m}), 10000(2,0 \times 0,5 \mathrm{~m})$ e 20000 $(1,0 \times 0,5 \mathrm{~m})$ e critérios para início das irrigações $(-20,-80,-140$ e -200 kPa, manejo SISDA 3-5응 e sem irrigação). Foram estabelecidos vários planos de amostragem para as variáveis altura de planta, diâmetro de caule e diâmetro de copa em função de diferentes números de repetições e de plantas por parcela. Há redução no coeficiente de variação com o aumento do número de plantas por parcela. O diâmetro de caule apresentou maior variabilidade que altura de planta. As estimativas das diferenças mínimas significativas entre duas médias de tratamentos decrescem com aumento do número de repetições e com o aumento do número de plantas por parcela.
\end{abstract}

Palavras-chave: diferença mínima significativa, tamanho de amostra, precisão experimental, cafeeiro irrigado

\section{Sampling plans in the initial development of the irrigated coffee}

\begin{abstract}
The objective of this study was to evaluate the characteristics of Rubi MG1192 coffee plant and depending on variability of characteristics establish sampling plans for guidence of projects. The treatments consisted of five densities 2,500 (4.0x1.0 m), 3,000 (3.0x1.0 m), $5,000(2.0 \times 1.0 \mathrm{~m}), 10,000(2.0 \times 0.5 \mathrm{~m})$ and 20,000 plants ha ${ }^{-1}(1.0 \times 0.5 \mathrm{~m})$ and five irrigation scheduling criteria $\left(-20,-80,-140\right.$ and $-200 \mathrm{kPa}$ and SISDA3.5 $5^{\circ}$ irrigation scheduler and no irrigation). The planting was accomplished in January, 2001. A completely randomized block design was used with four replications in split-plot. In the main plot were located the plant spacings and in the subplots the irrigation. Sampling plans were established for plant height and diameter of stem and the treetop of coffee plant for various numbers of replications and various numbers of plants per plot. Number of plants and the number of replications were important in the reduction of variability. The coefficient of variation decreased with increased number of plants per plot. The stem diameter showed most variablility as compesed to height and treetop.
\end{abstract}

Key words: least significant difference, sample size, experimental precision

\section{INTRODUÇÃO}

A amostragem adequada da parcela é fator importante para a validade dos resultados experimentais, devendo a parcela possuir dimensão tal que confira grau satisfatório de representatividade. Além do procedimento de coleta, existe preocupação do pesquisador em determinar um tamanho ótimo para a amostra que será tomada na parcela experimental. Aliado 
ao tamanho, tem-se ainda o interesse em achar o número ideal de repetições, para que se possa detectar pequenas diferenças entre tratamentos, sem incorrer em custos desnecessários.

A grande parte dos trabalhos envolvendo amostragem de plantas em café adota procedimentos bastante variáveis, com o tamanho da parcela variando de uma a 30 plantas (Fazuoli et al., 2000; Veneziano \& Fazuoli, 2000; Bartholo et al., 2003). Nos primeiros experimentos conduzidos no campo com cafeeiros, utilizavam-se parcelas constituídas por 25 a 50 plantas; todavia, devido ao aprimoramento das técnicas de pesquisa e custeios envolvidos, surgiu a necessidade de redução do tamanho da parcela experimental, buscando-se minimizar custos sem afetar a qualidade dos resultados nem os valores obtidos.

Trabalhos de pesquisa com a cultura do café são realizados em várias localidades e em ambientes diversificados, em que a heterogeneidade das condições ambientais pode acarretar erros experimentais elevados, o que dificulta a comprovação estatística de diferenças entre tratamentos. O uso de parcelas com tamanho ótimo pode reduzir a área experimental e aumentar a precisão dos experimentos, devido à redução do erro experimental (Lin et al., 1996; Steel et al., 1997)

Resultados sobre a variabilidade em experimentos de seleção têm sido relatados. Estudos de componentes de variância indicaram que o menor valor da estimativa da média de determinada progênie ou linhagem, ocorre com parcelas de uma única cova e maior número de repetições. O coeficiente de variação usando-se uma cova por parcela e 6 a 9 repetições, atingiu valor de 17,5\% (Monaco \& Rocha, 1965). Estudos comparativos revelaram menor coeficiente de variação para tratamentos com uma e quatro plantas (Monaco \& Fazuoli, 1975).

A partir de dados de produção de café cereja, variedade Catuaí amarelo, com idade de 3 anos, obtidos em experimento de uniformidade formado de 12 fileiras com 12 plantas em cada fileira, no espaçamento de $2,8 \times 1,0 \mathrm{~m}$, verificou-se um tamanho ótimo de parcela de $16,8 \mathrm{~m}^{2}$ ou 6 plantas (Viana et al., 2000).

A necessidade de identificação do melhor tamanho de parcela é evidente nos vários programas de avaliação de pesquisas; nesses casos, a capacidade de detecção de pequenas diferenças é essencial para o sucesso de identificação de técnicas mais adequadas, visto que as diferentes fases de uma cultura e os aspectos ambientais afetam, de modo diferente, os resultados.

Com o presente trabalho objetivou-se avaliar o efeito do número de plantas por parcela e do número de repetições sobre a variabilidade de algumas características de plantas de cafeeiro, no estágio de desenvolvimento inicial, estabelecendo-se planos de amostragem em função de combinações entre número de repetições e de plantas por parcela; para tanto, utilizaram-se dados oriundos de um experimento instalado em área experimental do Departamento de Agricultura da Universidade Federal de Lavras, com a finalidade de avaliar diferentes espaçamentos e critérios de irrigação na cultura do cafeeiro, no qual foram tomados dados individuais por planta.

\section{MATERIAL E MÉTODOS}

O experimento com o cafeeiro, conduzido sob variadas condições de irrigação e diferentes densidades de plantio, está instalado em área de pesquisa da Universidade Federal de Lavras, MG. A área está situada na altitude de $910 \mathrm{~m}$, latitude sul de $21^{\circ} 14$ e longitude oeste de $45^{\circ} 00^{\prime}$. O plantio foi realizado em janeiro de 2001, utilizando-se mudas sadias de cafeeiro, variedade Rubi-MG 1192. Os tratos culturais são realizados conforme a necessidade e recomendação, enquanto a calagem e adubações são de acordo com a análise de solo, além de baseadas nas recomendações para uso de corretivos e fertilizantes em Minas Gerais - 4a aproximação, Comissão de Fertilidade do Solo do Estado de Minas Gerais (CFSEMG, 1989) para o cafeeiro em fase de formação.

O delineamento experimental é o de blocos casualizados com quatro repetições, com os tratamentos em esquema de parcelas subdivididas, sendo que na parcela se localizam os espaçamentos e, na subparcela, a irrigação. Os tratamentos são cinco densidades de plantio: 2.500 plantas ha-1 ${ }^{-1}(4,0 \times 1,0$ m), 3.333 plantas.ha $^{-1}(3,0 \times 1,0 \mathrm{~m}), 5.000$ plantas ha $^{-1}(2,0 \times 1,0$ m), 10.000 plantas.ha-1 $(2,0 \times 0,5 \mathrm{~m})$ e 20.000 plantas ha $^{-1}(1,0 \mathrm{x}$ $0,5 \mathrm{~m})$, combinadas com seis momentos de irrigação: -20, -80, 140 e $-200 \mathrm{kPa}$, sem irrigação e balanço hídrico com monitoramento através do programa SISDA $3.5^{\circledR}$ (O software SISDA versão 3.5, atualmente denominado IRRIGA, é um programa para manejo de irrigação, no qual os dados climáticos são monitorados diariamente usando-se estação meteorológica automática, instalada na área do experimento; os dados são inseridos no programa o qual executa o cálculo da irrigação de cada parcela). Utilizou-se o método de irrigação localizada, com sistemas de filtragem de areia e discos, com gotejadores Carborundum de 3,8 $\mathrm{L} \mathrm{ha}^{-1}$, espaçados 0,40 m (determinado após teste para verificação do bulbo molhado). A parcela experimental constituiu-se de uma amostra de oito plantas úteis, nas quais foram realizadas as avaliações: medidas de altura de planta (da base do caule - superfície do solo até a extremidade apical do caule); diâmetro de caule (medido a uma altura de 4 cm do solo, no sentido da maior dimensão do caule) e diâmetro da copa (medido na altura do terço médio da planta).

Para cada variável estabeleceram-se relações entre o coeficiente de variação no nível de plantas e diferentes tamanhos de parcelas ou número de plantas por parcela, através da seguinte expressão:

$$
\text { C.V. }=100\left(\sqrt{\hat{\sigma}^{2}+\hat{\sigma}_{\mathrm{P}}^{2} / \mathrm{n}}\right) / \bar{y}
$$

em que C.V. é o coeficiente de variação (\%); n é o número de plantas por amostra ou o tamanho da amostra; $\bar{y}$ é a média geral do experimento; $\hat{\sigma}^{2}$ é a estimativa do componente de variância referente à repetição e $\hat{\sigma}_{P}^{2}$ a estimativa do componente de variância de plantas.

O número de plantas adequado para amostragem da parcela foi determinado pelo método da máxima curvatura, conforme Federer (1955), que sugeriu a construção de um gráfico de duas dimensões, em cujo eixo das abscissas são tomados os diferentes números de plantas por parcela e, no eixo das ordenadas, os respectivos coeficientes de variação. Traça-se uma curva através das coordenadas resultantes e se determina, por inspeção, o ponto de máxima curvatura, em que o valor da abscissa corresponde ao número adequado de plantas por 
parcela. Para determinar o ponto adequado, depois de traçada a curva, unem-se os dois pontos extremos através de uma reta, e o local da curva de maior distância a esta reta é o ponto de máxima curvatura (Gomez \& Gomez, 1984). Este ponto é aquele em que o aumento no tamanho da parcela não produz decréscimo marcante no coeficiente de variação.

Planos de amostragem foram dimensionados a partir da diferença mínima significativa que se pretende discriminar entre duas médias de tratamento. Esta diferença foi estimada pela expressão:

$$
\operatorname{DMS}=\mathrm{q}_{(5 \%)}\left(\left(\hat{\sigma}^{2}+\hat{\sigma}_{\mathrm{P}}^{2} / \mathrm{n}\right) / \mathrm{r}\right)^{\wedge} 0,5
$$

em que DMS é a diferença mínima significativa entre duas médias de tratamentos; $\mathrm{q}_{(5 \%)}$ é o valor crítico da amplitude estudentizada para aplicação do teste Tukey a 5\% de probabilidade e r é o número de repetições. Este valor foi obtido em função das várias combinações dos números de repetições e plantas.

\section{RESULTADOS E DISCUSSÃO}

O esquema de análise de variância mostrando os graus de liberdade e os componentes de variância do modelo adotado, em blocos casualizados, com tomada de oito plantas por repetição, está apresentado na Tabela 1 . Os fatores irrigação e espaçamento foram considerados de efeitos fixos, enquanto os efeitos de bloco e de plantas foram tomados como aleatórios (Barbin, 1993; Montgomery, 2001).

Tabela 1. Esquema de análise de variância mostrando as fontes de variação, números de graus de liberdade e esperança matemática dos quadrados médios

Fonte de variação $\quad$ G.L. $\quad$ E (Quadrado médio) ${ }^{1}$

\begin{tabular}{|c|c|c|}
\hline Espaçamento & 4 & $\sigma_{\mathrm{P}}^{2}+8 \sigma^{2}+48 \sigma_{\mathrm{B}}^{2}+192 \mathrm{f}(\mathrm{E})$ \\
\hline Blocos (Espaçamento) & 15 & $\sigma_{\mathrm{P}}^{2}+8 \sigma^{2}+48 \sigma_{\mathrm{B}}^{2}$ \\
\hline Irrigação & 5 & $\sigma_{\mathrm{P}}^{2}+8 \sigma^{2}+160 \mathrm{f}(\mathrm{I})$ \\
\hline Espaçamento x irrigação & 20 & $\sigma_{P}^{2}+8 \sigma^{2}+32 f(E x I)$ \\
\hline Erro experimental & 75 & $\sigma_{\mathrm{P}}^{2}+8 \sigma^{2}$ \\
\hline Erro entre plantas & 840 & $\sigma_{\mathrm{P}}^{2}$ \\
\hline
\end{tabular}

Para aplicação do teste $\mathrm{F}$ verifica-se que o denominador para espaçamento é QM de blocos(espaçamento) e para irrigação e interação espaçamento $\mathrm{x}$ irrigação é o erro experimental; o erro entre plantas é o denominador do teste $\mathrm{F}$ para erro experimental.

As médias gerais das características avaliadas e as estimativas dos componentes de variância são apresentadas na Tabela 2. O componente de variância referente a plantas foi maior que o componente referente à repetição (ou erro) para todas as características estudadas, sugerindo que a
Tabela 2. Valores médios de altura de planta $(\mathrm{cm})$, diâmetro de caule $(\mathrm{mm})$ e diâmetro da copa $(\mathrm{cm})$ e respectivas estimativas dos componentes de variância de erro experimental (repetições) e de plantas, no desenvolvimento inicial da variedade do cafeeiro Rubi-MG 1192, cultivada sob diferentes critérios de irrigação

\begin{tabular}{|c|c|c|c|}
\hline \multirow[b]{2}{*}{ Parâmetros } & \multicolumn{3}{|c|}{ Variáveis } \\
\hline & $\begin{array}{l}\text { Altura de } \\
\text { Planta }(\mathrm{cm})\end{array}$ & $\begin{array}{l}\text { Diâmetro de } \\
\text { Caule (mm) }\end{array}$ & $\begin{array}{c}\text { Diâmetro da } \\
\text { Copa }(\mathrm{cm})\end{array}$ \\
\hline Média geral & 36,0700 & 10,6000 & 67,4000 \\
\hline Componente do erro & 1,0704 & 0,3563 & 7,0921 \\
\hline $\begin{array}{l}\text { Componente de } \\
\text { plantas }\end{array}$ & 14,5134 & 15,8384 & 50,0110 \\
\hline
\end{tabular}

amostragem das plantas na parcela é fator importante e que pode afetar, de modo considerável, os resultados.

\section{Variabilidade: coeficiente de variação}

A representação gráfica do coeficiente de variação em função de diferentes números de plantas por parcela está indicada na Figura 1. Observa-se redução no coeficiente de variação para as três variáveis com o incremento no número de plantas e comportamento diferenciado de acordo com a característica, sendo maiores para diâmetro do caule e menores para a altura de planta. Os coeficientes de variação apresentaram valores entre 2,98 e $28,84 \%$, sendo inversamente proporcionais ao número de plantas por parcela; esta redução no coeficiente de variação não foi linear, foi mais acentuada no início e, mais adiante, mostrou tendência à estabilidade. $\mathrm{O}$ aumento do número de plantas nas parcelas é bom até determinado ponto, a partir do qual o uso de maior quantidade de plantas não é compensado pelos baixos ganhos de precisão.

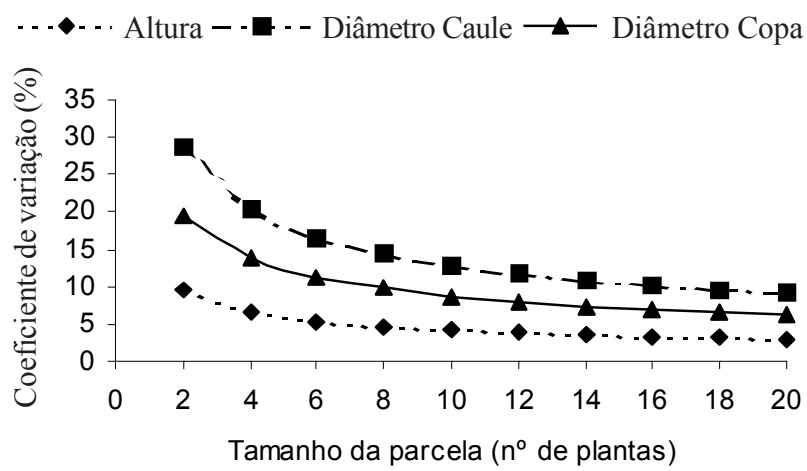

Figura 1. Representação gráfica do coeficiente de variação das variáveis: altura de planta, diâmetro do caule e da copa, em função do número de plantas por parcela, da cultivar de café Rubi-MG 1192, em início de desenvolvimento

Os maiores decréscimos ocorreram quando o número de plantas aumentou de duas para quatro, sendo esta diferença maior para o diâmetro do caule seguido pelo diâmetro da copa; para essas duas variáveis, observa-se ainda um decréscimo acentuado, quando o número de plantas passou de quatro para seis e de seis para oito. A partir de oito plantas ainda 
ocorrem decréscimos na variabilidade, mas já com intensidade menor.

Pelo método da máxima curvatura o melhor tamanho de parcela, para as três características, foi de oito plantas; valor próximo aos utilizado por Viana et al. (2000).

Para se ter uma idéia da variabilidade entre as variáveis, constata-se coeficientes de variação da ordem de $10 \%$ com o uso de duas plantas para altura de planta, sete para diâmetro da copa e 17 plantas para diâmetro do caule; assim, com oito plantas tem-se coeficientes de variação de $4,7 \%$ para altura de planta, 9,8\% para diâmetro da copa e 14,4\% para diâmetro do caule; valores próximos e menores a $17,5 \%$ citado por Monaco \& Rocha (1965).

\section{Planos de amostragem: diferença mínima significativa}

Os planos de amostragem que permitem estabelecer-se o número ideal de repetições e de plantas por parcela, necessários para detectar uma diferença mínima significativa entre duas médias de tratamento para altura de planta, diâmetro de caule e diâmetro da copa estão na Tabela 3 .

A análise desta tabela revela que as diferenças mínimas significativas decrescem ao se aumentar o número de repetições por tratamento, o mesmo se verificando com aumento do número de plantas; além disso, aumentar o número de repetições e de plantas acima de certo limite, fornece pequenas reduções na diferença mínima significativa. Para altura de planta verifica-se que, para detectar uma diferença mínima significativa da ordem de $10 \%$ da média do experimento, por exemplo, o que corresponde a aproximadamente $3,6 \mathrm{~cm}$, pode-se planejar um experimento com 6 repetições por tratamento e 6 plantas por repetição, 4 repetições e 10 plantas, 10 repetições e 4 plantas, ou seja, esses planos apresentam a mesma eficiência, enquanto a escolha de outro melhor fica a critério do pesquisador.

Os planos de amostragem com base no diâmetro do caule podem ser estabelecidos a partir dos valores apresentados na Tabela 3. Para se detectar uma diferença mínima significativa entre duas médias de tratamento de $2 \mathrm{~mm}$, por exemplo, recomenda-se a coleta de 14 plantas por repetição, em 6 repetições ou, então, a coleta de 20 plantas por repetição, em 4 repetições; já uma diferença de $10 \%$ da média, que corresponde a $1,1 \mathrm{~mm}$, somente é esperada que ocorra usando-se 12 repetições com 20 plantas cada uma, devido à maior variabilidade inerente à característica diâmetro do caule em relação à altura da planta. Características mais variáveis necessitam de uma amostragem maior para serem avaliadas com a mesma precisão de outra que possui menor variabilidade.

Para diâmetro da copa (Tabela 3 ) espera-se que uma diferença mínima significativa entre duas médias de tratamento de 6,7 cm, por exemplo, seja detectada com uma amostragem de 6 plantas coletadas em 8 repetições ou com o uso de 4 repetições, coletando-se 12 plantas em cada repetição; esses planos possuem eficiência semelhante, entre outros que podem ser construídos. Barbin (1993) ressalta que, aumentando-se o número de repetições, a variabilidade tende a diminuir, porém é mais eficiente quando $\hat{\sigma}^{2}>\hat{\sigma}_{P}^{2}$, fato que não ocorreu neste caso, sugerindo que o número de plantas e o de repetições reduziram a variabilidade.
Tabela 3. Diferenças mínimas significativas entre duas médias de tratamento para altura de planta, diâmetro do caule e diâmetro da copa, da cultivar de café Rubi-MG 1192, em diferentes combinações entre o número de repetições por tratamento e o número de frutos por repetição, a $5 \%$ de probabilidade, respectivamente.

\begin{tabular}{|c|c|c|c|c|c|c|}
\hline \multirow{2}{*}{$\begin{array}{l}\text { Número } \\
\text { de } \\
\text { Plantas }\end{array}$} & \multicolumn{6}{|c|}{ Número de Repetições } \\
\hline & 2 & 4 & 6 & 8 & 10 & 12 \\
\hline \multicolumn{7}{|c|}{ Altura de Planta - cm } \\
\hline 2 & 11,5 & 7,9 & 6,3 & 5,5 & 4,9 & 4,4 \\
\hline 4 & 8,1 & 5,6 & 4,5 & 3,9 & 3,5 & 3,2 \\
\hline 6 & 6,7 & 4,5 & 3,7 & 3,2 & 2,8 & 2,6 \\
\hline 8 & 5,8 & 3,9 & 3,2 & 2,7 & 2,4 & 2,2 \\
\hline 10 & 5,2 & 3,5 & 2,8 & 2,4 & 2,2 & 2,0 \\
\hline 12 & 4,7 & 3,2 & 2,6 & 2,2 & 2,0 & 1,8 \\
\hline 14 & 4,4 & 3,0 & 2,4 & 2,1 & 1,8 & 1,7 \\
\hline 16 & 4,1 & 2,8 & 2,2 & 1,9 & 1,7 & 1,6 \\
\hline 18 & 3,8 & 2,6 & 2,1 & 1,8 & 1,6 & 1,5 \\
\hline 20 & 3,6 & 2,5 & 2,0 & 1,7 & 1,5 & 1,4 \\
\hline \multicolumn{7}{|c|}{ Diâmetro do Caule - mm } \\
\hline 2 & 9,9 & 6,8 & 5,5 & 4,7 & 4,2 & 3,8 \\
\hline 4 & 7,0 & 4,8 & 3,9 & 3,3 & 3,0 & 2,7 \\
\hline 6 & 5,7 & 3,9 & 3,2 & 2,7 & 2,4 & 2,2 \\
\hline 8 & 5,0 & 3,4 & 2,7 & 2,4 & 2,1 & 1,9 \\
\hline 10 & 4,4 & 3,0 & 2,4 & 2,1 & 1,9 & 1,7 \\
\hline 12 & 4,1 & 2,8 & 2,2 & 1,9 & 1,7 & 1,6 \\
\hline 14 & 3,8 & 2,6 & 2,1 & 1,8 & 1,6 & 1,5 \\
\hline 16 & 3,5 & 2,4 & 1,9 & 1,7 & 1,5 & 1,4 \\
\hline 18 & 3,3 & 2,3 & 1,8 & 1,6 & 1,4 & 1,3 \\
\hline 20 & 3,1 & 2,1 & 1,7 & 1,5 & 1,3 & 1,2 \\
\hline \multicolumn{7}{|c|}{ Diâmetro da Copa - cm } \\
\hline 2 & 24,6 & 16,8 & 13,6 & 11,7 & 10,5 & 9,5 \\
\hline 4 & 17,4 & 11,9 & 9,6 & 8,3 & 7,4 & 6,7 \\
\hline 6 & 14,2 & 9,7 & 7,8 & 6,8 & 6,0 & 5,5 \\
\hline 8 & 12,3 & 8,4 & 6,8 & 5,9 & 5,2 & 4,8 \\
\hline 10 & 11,0 & 7,5 & 6,1 & 5,2 & 4,7 & 4,3 \\
\hline 12 & 10,1 & 6,9 & 5,5 & 4,8 & 4,3 & 3,9 \\
\hline 14 & 9,3 & 6,4 & 5,1 & 4,4 & 4,0 & 3,6 \\
\hline 16 & 8,7 & 5,9 & 4,8 & 4,1 & 3,7 & 3,4 \\
\hline 18 & 8,2 & 5,6 & 4,5 & 3,9 & 3,5 & 3,2 \\
\hline 20 & 7,8 & 5,3 & 4,3 & 3,7 & 3,3 & 3,0 \\
\hline
\end{tabular}

A escolha de um plano de amostragem deve adequar-se à disponibilidade de repetições, de plantas, ao custo de coleta e das análises a serem realizadas. O planejamento de amostragem apresentado, pressupõe que as estimativas de variabilidade entre repetições e entre plantas sejam representativas da variabilidade que se pode encontrar em trabalhos com cafeeiro em início de desenvolvimento. Se o pesquisador acredita que as condições ambientais são semelhantes às do seu experimento a ser instalado, os planos estabelecidos são sugeridos para se atingir precisão satisfatória; entretanto, se as condições ambientais podem variar grandemente deste experimento para o seu, não se recomenda usar os planos propostos.

Para detectar pequenas diferenças entre médias, exige-se maior número de repetições ou de plantas por repetição. Caso não seja necessário pequenas diferenças, um número menor de plantas por parcela será requerido; como exemplo, se for desejável detectar uma diferença de $20 \%$ da média, poderão ser utilizados quatro repetições constituídas de quatro plantas 
para altura de planta e diâmetro de copa, e de vinte plantas para diâmetro de caule, mas, de acordo com o resultado do método da máxima curvatura, o uso de mais que oito plantas não acarreta ganho substantivo na precisão experimental.

As estimativas do tamanho das parcelas aqui obtidas estão próximas aos valores encontrados na literatura: 6 plantas (Viana et al., 2000), 1 a 30 plantas (Fazuoli et al., 2000; Bartholo et al., 2003) e 24 plantas (Silva et al., 2003).

\section{CONCLUSÕES}

1. Há redução no coeficiente de variação com o aumento do número de plantas avaliadas por parcela.

2. O diâmetro de caule é uma característica que possui maior variabilidade em relação à altura de planta.

3. Diferenças mínimas significativas entre duas médias de tratamentos decrescem com o aumento do número de repetições e com o aumento do número de plantas por parcela.

4. Quando houver interesse em detectar diferença significativa entre duas médias de tratamentos da ordem de $10 \%$ da média do experimento, usando-se quatro repetições, sugere-se utilizar ao menos 10, 20 e 12 plantas por parcela, respectivamente, para altura de planta, diâmetro do caule e diâmetro da copa.

\section{LITERATURA CITADA}

Barbin, D. Componentes de variância: teoria e aplicações. 2.ed. Piracicaba: FEALQ, 1993. 120p.

Bartholo, G.F.; Guimarães, P.T.G.; Mendes, A.N.G. Produtividade de cultivares de cafeeiros (Coffea arabica L.) submetidas a diferentes épocas de parcelamento da adubação. Ciência e Agrotecnologia, Lavras, v.27, n.4, p.816-821, 2003.

CFSEMG - Comissão de Fertilidade do Solo de Minas Gerais. Recomendações para o uso de corretivos e fertilizantes em Minas Gerais: 4ª Aproximação. Lavras: UFLA, 1989. 176p.
Fazuoli, L.C.; Guerreiro Filho, O.; Silva Rolla, M.B.; Medina Filho, H.P. Avaliação das cultivares Mundo Novo, Bourbom amarelo, Bourbom vermelho de Coffea arabica em Campinas. In: Simpósio de Pesquisa dos Cafés do Brasil, 1, Poços de Caldas, 2000. Resumos expandidos... Brasília: Embrapa Café/MinasPlan, 2000. p.451-458.

Federer, W.T. Experimental design. New York: McMillian, 1955. $544 \mathrm{p}$.

Gomez, K.A.; Gomez, A.A. Statistical procedures for agricultural research. 2.ed. New York: John Wiley, 1984. 680p.

Lin, C.S.; Morrison, M.J.; Binns, M.R. Persistence on a field heterogeneity index. Canadian Journal of Plant Science, Ottawa, v.76, n.1, p.245-250, 1996.

Monaco, L.C.; Fazuoli, L.C. Melhoramento do cafeeiro. XXXV - Altura e produtividade das plantas e características das sementes de progênies e híbridos de café plantados a uma e quatro plantas por cova. Bragantia, Campinas, v.34, n.1, p.295-308, 1975.

Monaco, L.C.; Rocha, T.R. Melhoramento do cafeeiro. XXVIII - Ensaios de seleções regionais em Mococa. Bragantia, Campinas, v.24, n.1, p.9-27, 1965.

Montgomery, D.C. Design and analysis of experiments. 5.ed. New York: John Wiley, 2001. 684p.

Silva, A.L.; Faria, M.A.; Reis, R.P. Viabilidade técnicoeconômica do uso do sistema de irrigação por gotejamento na cultura do cafeeiro. Revista Brasileira de Engenharia Agrícola e Ambiental, Campina Grande, v.7, n.1, p.37-44, 2003.

Steel, R.G.D.; Torrie, J.H.; Dickey, D.A. Principles and procedures of statistics: a biometrical approach. 3.ed. New York: McGraw-Hill, 1997. 666p.

Veneziano, W.; Fazuoli, L.C. Avaliação de cultivares de cafeeiros robusta (Coffea canephora) em Rondônia. In: Simpósio de Pesquisa dos Cafés do Brasil, 1, 2000. Poços de Caldas. Resumos expandidos... Brasília: Embrapa Café/MinasPlan, 2000. p.459-461.

Viana, A.E.S.; Doll, E.T.; Sales Júnior, S.G.; Santos, P.R.P. Tamanho da parcela em experimentos com cafeeiros (Coffea arabica L.). In: Simpósio de Pesquisa dos Cafés do Brasil, 1, 2000. Poços de Caldas. Resumos expandidos... Brasília: Embrapa Café/MinasPlan, 2000. p.1064-1067. 